\title{
Higher Vocational English Micro Teaching in the Information Environment
}

\author{
Qingjuan $\mathrm{Ma}$ \\ Tianjin Vocational Institute, Tianjin, 300410, China
}

Keywords: information, higher vocational English, micro teaching

\begin{abstract}
Micro teaching can not only provide students with individualized learning conditions and enrich knowledge spreading ways and means, but also build a teacher communication platform, promote teachers' professional development and facilitate promotion of continuous deepening of education and teaching reform in higher vocational colleges. This paper begins with the connotation and characteristics of micro courses, and discusses about the importance of introducing micro teaching to higher vocational English and specific strategies of implementing micro teaching in the information environment.
\end{abstract}

\section{Connotation and characteristics of micro courses}

\section{(I) Connotation of micro courses}

Micro course is a novel teaching form, and can be literally understood as a teaching model with short teaching time and less content. Specifically speaking, micro courses refer to online teaching videos with the goal of interpreting certain knowledge, the main form of online videos with short time and concise content and the purpose of learning and teaching application. Thus, video is the main form of micro courses with ultimate goal of highlighting teaching focus. According to specific functions, micro courses can be divided into the following categories: question answering, problem solving, lectures, and experiment etc. Under micro teaching model, teaching video is the core component with a time length of about 20 minutes, and there are also some relevant auxiliary teaching resources, such as teaching courseware, materials, teaching summary and test practice etc. Through the above analysis, it can be easily seen that although micro courses are different from traditional teaching resources, there is still connection to a certain degree, and micro courses are new teaching resources based on traditional resources. It shall be clarified that one micro course is generally corresponding to only one category of courses as well as a combination of above two categories of micro courses. In other words, the classification standard is not unique but open to a certain degree. With the continuous development of modern education and teaching theory, teaching method makes considerable progress, in which context, a lot of new teaching models and methods are created including micro courses. Although this teaching model has been put forward for a short time, it wins wide concern and recognition of the education circle with many advantages. (II) Characteristics of micro courses

1. Clear and prominent subjects

Clear course goals are one of distinctive characteristics of micro courses, and are specifically reflected in the following two aspects: on the one hand, micro courses are all based on certain knowledge or teaching link of a discipline and thus have very clear goals; on the other hand, the goals are very clear, i.e. serve for higher vocational teaching and ensure smooth implementation of researches on relevant subjects. With clear and prominent subjects, micro courses become an effective way and means of higher vocational teaching, and highlight the superiority especially in the information environment.

2. Short and concise content

Compared with traditional classroom teaching, micro courses fully reflect advantages of being "micro", i.e. short time and concise content, as such courses usually express certain knowledge or teaching link in the form of multimedia, have matching data traffic between more than ten megabytes and dozens of megabytes, and thus enable convenient network transmission and data sharing. 


\section{Rich and diversified resources}

As micro courses have teaching videos as the carrier and could provide learners with many resources like teaching courseware, exercises and teacher-student interaction etc, a rich and diversified teaching environment can be built. Meanwhile, micro courses have a relatively independent structure and are built on the basis of certain knowledge or teaching link, and all knowledge modules are independent from each other. If several knowledge modules are combined together organically to form a comprehensive and systematic learning unit, a complete structured resource environment is established.

4. Convenient interaction and sharing

With detailed, specific, short and concise content, micro courses can display implicit knowledge in a linear way, which is convenient to exchange and comment, and conducive to promoting teachers' professional development. Meanwhile, videos are short, and thus can attract students' attention easier and help achieve sharing of teaching resources. Besides, learning objects of micro courses will not be restricted by time and space, so that students could learn independently, and teachers could interact with students through micro courses and optimize teaching design according to students' feedback, which can help promote continuous improvement of teaching methods and significantly enhance teaching effects.

\section{Importance of introducing micro teaching to higher vocational English}

Micro teaching, a new modern teaching method with many teaching advantages, is bound to achieve good teaching effects if introduced to higher vocational English course teaching.

(I) Conducive to students' individualized learning

Students in higher vocational colleges have generally weak English foundation, and mostly still maintain at English proficiency of middle school, and would often have low efficiency when learning boring knowledge. To improve this teaching status, teachers shall enhance vitality and interest in teaching activities and stimulate students' interest in learning. Micro teaching is carried out after teachers' careful preparation, and has teaching content and design carefully considered by teachers, and teachers have put lots of energy at the preparation stage before class although it takes a short time. Micro teaching of higher vocational English classroom can improve utilization efficiency of class time, so that students could master key theoretical knowledge within a short time, and reserve enough time for practice teaching and train their practical ability. At the same time, rich micro teaching resources can provide favorable conditions for students' independent learning after class, and thus promote students' individualized learning and continuous improvement of English self-learning ability, and create new learning experience.

(II) Conducive to promoting teachers' professional development

In traditional English classroom teaching activities, teachers of higher vocational colleges generally teach students in their colleges, so that the positive role of classroom teaching of excellent teachers is not given full play to. Micro courses provide opportunities for teachers to show their teaching style, and teachers could publish excellent micro courses on the internet for positive feedback and evaluation of learners and professionals, and communicate and interact with students or other teachers through micro course platform, and thus find out their insufficiencies in teaching and make improvement. This is conducive to promoting improvement of teachers' professional qualities and constant enhancement of their English teaching level.

(III) Conducive to enriching knowledge spreading means

Micro teaching of higher vocational English can enrich knowledge spreading ways and means and expand students' learning ways. Micro course is a type of classroom teaching method based on the internet and mobile terminal devices, and the combination of internet with classroom teaching enables convenient and fast spreading of knowledge and skills, so that students could master key knowledge within a short time. Meanwhile, micro teaching is also a learning way that students have interest and could change students' traditional learning habits and make students open up new ways of mobile learning.

(IV) Conducive to building a teacher communication platform 
Micro teaching of higher vocational English can not only show teaching style of colleges, but also learn from and refer to teaching experience of excellent teachers in other colleges, build a teacher communication platform, give feedback and evaluation of each other, and improve teaching methods constantly. Meanwhile, on the communication platform, teachers could discuss about difficulties in teaching, put heads together, and seek the best method to solve teaching difficulties, and thus optimize classroom teaching effects and improve overall teaching level of higher vocational English.

\section{Implementation of micro teaching of higher vocational English in the information environment}

(I) Select micro video recording methods rationally

Micro video recording is one of vital links of micro teaching, and has commonly used recording methods mainly including: picture recording, video recording and combination of both. To ensure full play of the teaching role of micro videos, teachers of higher vocational colleges shall select appropriate recording methods during video recording. For using micro videos in higher vocational English classes, teachers are suggested to record in the way of video recording as much as possible, as this method is simple and teachers could record before classes with generally a notebook computer with earphone and microphone. Meanwhile, while recording PPT presentations, teachers can suspend at any time or modify recorded content. In addition, while recording videos, teachers could add voice explanation in videos and emphasize key content by subtitle, so as to concentrate all knowledge into short video clips; although high definition can be obtained through picture recording, expensive device is required, otherwise recording effects will be affected with poor shooting; if allowed, combine both of recording methods, for example, add some live scenes appropriately while recording videos, or insert video PPT during picture recording. While combining both video recording methods, do good work in post processing, which is directly related to video effects. In short, as a teaching tool in the information environment, micro course is bound to be widely used in higher vocational English teaching.

(II) Enrich micro teaching methods

To deepen teaching structure reform of higher vocational colleges, rich teaching methods such as flipped classroom etc shall be actively introduced, in order to give full play to teaching advantages of micro courses and provide students with diversified and individualized learning conditions.

1. Introduce micro courses to classroom teaching. Micro courses can be introduced to the whole classroom teaching of higher vocational English, and micro teaching can be carried out at different teaching nodes before, during and after classes. In terms of introducing micro teaching before classes, teachers let students learn micro courses independently before classes, discuss about and solve problems commonly during classes, and help students master knowledge, so as to complete knowledge spreading before classes and achieve knowledge construction during classes. This teaching method is also the specific reflection of flipped classroom teaching model. In terms of introducing micro teaching during classes, teachers could play micro courses as teaching resources to students at appropriate teaching time, so that students could better understand difficulties and keys of knowledge. In terms of using micro teaching after classes, teachers could provide students with micro video resources, so that students could review keys of the course with such resources after classes and learn independently until understand and master.

2. Take micro courses as real classroom teaching. In teaching of higher vocational English, English can be divided into several micro courses and make micro courses form systematic ones, so that students complete learning course content while completing learning of micro courses. This teaching model of micro courses shall support mobile learning, so that teachers could master learning progress and status of each student and provide students with subsequent learning content according to their learning conditions.

(III) Design micro teaching organizations

To improve micro teaching quality of higher vocational English, the following shall be achieved:

1. Design teaching topics. Follow principles of purpose, interest, education and application when 
design content of micro courses, and design elaborately around teaching topics. Make clear what to teach first and students' basic conditions etc, and then design overall teaching activities and exercises, prepare teaching materials, and determine software used for development of micro courses.

2. Cut to the point quickly. Due to short time of micro courses, it shall cut to the point quickly without preamble when introducing classroom teaching, in order to enhance teaching effects of micro courses. To cut to the point, questions can be set or review previously learned knowledge and even introduce from living phenomena around students. No matter in what way, introduction of topics shall be striking, in order to lay a foundation for teaching content and knowledge spreading in micro courses.

3. Lines of teaching shall be clear. During teaching of micro courses, teachers shall determine a main line around teaching objectives, and then teach each part of content orderly under the guidance of main line. Focus teaching on explanation and analysis of key knowledge, and deepen students' understanding and mastery of knowledge through simulation demonstration, inspiring guidance and illustration, so that students could acquire knowledge in a relatively loose learning environment.

4. Express vividly. Teaching of micro courses shall not only have good topic design and introduction, but also spread teaching content in a vivid, accurate and infectious language of teachers. During micro courses, teachers shall consider whether each sentence is appropriate with concise and simple meaning, and thus ensure that students could learn key knowledge within a short time.

5. Summarize micro courses. Summarize each class in the last part of micro teaching for not too long time, summarize and emphasize content of each class, to deepen students' impression of knowledge and bring out the crucial point.

\section{Conclusions:}

In a word, in the era of information, micro courses have become one of important teaching means that higher vocational colleges realize educational information. Micro courses shall be developed and utilized to a maximum degree in higher vocational English teaching, and be introduced before, during and after classes as important supplement and effective expansion of teaching resources of traditional classroom teaching, in order to build a platform of independent and individualized learning for students and thus improve English teaching effects constantly.

\section{Acknowledgments}

This paper is a 2013 annual project of Tianjin Higher Vocational and Technical Educational Research Association "Empirical Research on the Influence of Negative Transfer of Mother Tongue on English Writing of Higher Vocational Students” (Project Approval No.: XIII502).

\section{References}

[1] Yang Hongye. How Can Micro Courses Attract Learners: Ponderings for Video Recordings of China's $1^{\text {st }}$ Colleges' Micro Courses Competition [J]. China Educational Technique \& Equipment. 2013 (8).

[2] Hangzhou Vocational \& Technical College. The $1^{\text {st }}$ College Micro Course Competition Award Ceremony of Zhejiang Province and College Teaching Information Seminar in the Micro Era Is Held in Hangzhou Normal University [J]. Distance Education Journal. 2013 (12).

[3] Yang Manfu, Sang Xinmin. Deep Thinking of Micro Courses in MOOCS Tide-Analysis Based on the $1^{\text {st }}$ College Micro Course Competition [J]. Exploring Education Development, 2013 (11).

[4] Zhang Lianzhu. Analysis of the Prospect of "Micro Courses" in Application of Distance and Open Education [J]. Journal of Fujian Radio \& TV University. 2013 (10).

[5] Li Li, Gu Chaozhi, Li Shibao. Construction of Communication Course Teaching Platform Based on Micro Teaching Model [J]. Course Education Research. 2014 (1). 
[6] Wu Anyan, Chen Jiliang, Zhang Hongyi. Study on Teachers' Educational Skills Training Plan under the Concept of Micro Courses-A Case Study of Teacher Education of Shaoguan University [J]. Software Guide. 2013 (6).

[7] Zhang Qijing, Liu Yadong, Wang Bo. Study on Integrated Teaching Model of Higher Vocational English Teaching Comment Based on Micro Courses-A Case Study of Foreign Affairs Practice Course [J]. Journal of Hubei Correspondence University. 2013 (12). 